\title{
(Lantool) Power Generation Cost Minimization Software Application
}

\author{
Anireh V.I.E., ${ }^{1, *}$ John Tarilanyo Afa ${ }^{2}$ \\ ${ }^{1}$ Department of Electrical/Computer Engineering, Rivers State University of Science and Technology, Rivers State, Nigeria \\ ${ }^{2}$ Department of Electrical/Electronic Engineering, Niger Delta University, Bayelsa State, Nigeria \\ *Corresponding author: viaemeka@gmail.com
}

Received September 29, 2013; Revised December 25, 2013; Accepted January 10, 2014

\begin{abstract}
Managers of large scale industry like the electricity generation are challenged at many fronts because the tasks involved are complex, influenced by unexpected events and evolve in time. Currently the application of computer methods in this industry has produced tremendous positive results. In this regard, the study presents an effort developed to solve optimal power flow (economic dispatch) problem by minimizing the cost of generation using the lagrangian multiplier method. A decision support system 'Lantool' is presented. The approach is validated by lagrangian method found in technical literatures. The system will assist operators in thermal power plants with the task of planning generation in the most economic way. A result obtained from the application explains the important role decision support systems can play in the management of the electricity generation industry.
\end{abstract}

Keywords: optimal power flow, minimizing cost, economic dispatch, lagrangian multiplier method, decision support system

Cite This Article: Anireh V.I.E., and John Tarilanyo Afa, "(Lantool) Power Generation Cost Minimization Software Application.” American Journal of Electrical and Electronic Engineering 2, no. 1 (2014): 21-26. doi: 10.12691/ajeee-2-1-5.

\section{Introduction}

The rapid growth in power system industry has made the issue of optimization in power generation and transmission very significant. In the recent time, deregulation in power industry has changed the part played by various units in the electricity industry. Services provided by electric power vendors which originally used to be one single entity are now unbundled into three different entities thus production, transmission and distribution. The service providers' compete in providing good electricity delivery and at the same time strive to make profit. To maintain efficiency and security, reliability of supply are not compromised otherwise customer interest and protection will not be guaranteed. In other to achieve these, best practices in economic dispatch [1] or optimal power flow are employed. The objective is to systematically seek the lowest cost of electricity production that will be consistent with electricity demand. To minimize cost, Optimal power flow (OPF) will increase the use of more efficient generating unit and at the same time addresses two issues of concern - better fuel usage, and reduced green house gas emission $[2,3,4]$ that would result from less efficient generation. OPF therefore seeks to minimize the total cost of generating power (production cost) at various stations while satisfying the loads and the losses in the transmission lines. In the case of developing countries like Nigeria where consumption per capita of electricity is very poor mainly due to high cost of production [5], application of the principles of OPF cannot be over looked. Even when these principles are to be employed the approach to deliver it in a simpler and user friendly manner to enable operators effectively apply it is equally very necessary. It is in view of all these considerations that this paper seeks to present a computer based support system for the electricity generation industry. Computer applications in the form decision support system (DSS) can be a tool used to provide fair and consistent decisions, and at the same time improve the effectiveness of decision making process [6]. A DSS application approach for supporting decision making is typically built for solutions of a certain problem or to evaluate an opportunity. On that note, we present a decision support computer-based tool using Lagrangian multiplier method. The approach was applied to a five-bus network to minimize cost of electricity generation and result is also presented.

Many solution techniques have been proposed and also available to solving optimal power flow problem with varied degree of successes. They can be divided into two main categories, the algorithmic mathematical solution and artificial intelligent solution as reported in several literatures. Among the algorithmic solutions are Interior point (IP) algorithm [7], Simplex algorithm (SA), Quadratic programming (QP), and Dynamic programming (DP) [8]. Langrange relaxation method (LRM) $[9,10]$ Linear programming (LP), Non-linear programming (NLP) and Newton-based methods have also been reported. Currently proposed Artificial Intelligent optimization methods based on heuristics and operational research 
presented by researchers have emerged with global optimum solution for power system optimization. They include Expert system (ES), Ant Colony search (ACS) [11], Simulated annealing (SA) [12], Artificial Neural networks (ANN) [13,14,15], Fuzzy logic (FL) [16] and Genetic Algorithm (GA) [17]. Others include Meta heuristic methods such as Tabu search (TS) [18], Particle swarm optimization (PSO) [19,20] and Evolutionary programming (EP) [21,22]. Application of these methods depends on the researchers' area of interest as each method has its own advantages and disadvantages. Even as these optimization methods are effective in finding the global optimal solution, however, when adopted in largescale real-world system, it would take a long computational time. It therefore explains the fact that there exist a gap between theory and practice in the field of optimization. Attempt to bridge this gap is what this paper seek to present by shifting focus to applying analytical method to solving a real-world problem.

\subsection{OPF Formulations}

Generally, power system can be operated optimally if the principles of equal incremental cost rate are applied to the problem of optimal distribution of loads among the various stations forming a power pool. The most precise way to describe such operation is to use the relation between the input and output parameter as available from the generated data of the individual generators.

The characteristic of this relation is described mathematically as.

$$
I=a+b P+c P^{2}+d P^{3}+\ldots \ldots . n P^{r}
$$

Where I is the input (cost of fuel) and P is the output (power produced by generator) with positive coefficients a, $\mathrm{b}, \mathrm{c}$ to $\mathrm{n}$.

Alternatively it can be represented graphically as shown in Figure 1:

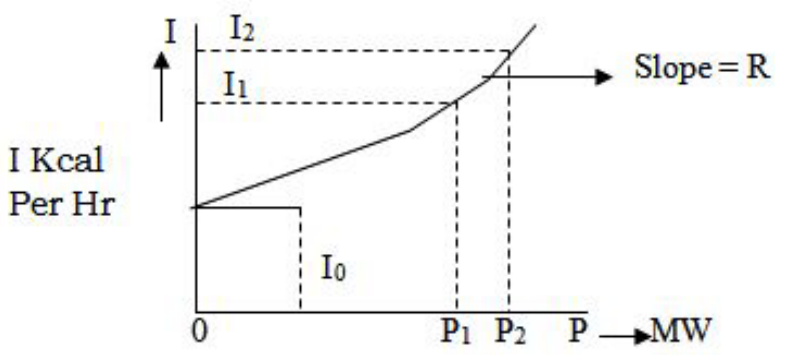

Figure 1. Input - output characteristic of a generator.

$\mathrm{I}_{0}$ in the above graph represents the amount of input required to keep the generator functioning when there is no load. The slopes of the curve at various load-points give the incremental cost rate. If $I_{1}$ and $I_{2}$ are the inputs corresponding to the loads $\mathrm{P}_{1}$ and $\mathrm{P}_{2}$ respectively, the increase in input required for meeting the increase of load from $\mathrm{P}_{1}$ to $\mathrm{P}_{2}$ is given by

$$
I_{2}-I_{1}=\int_{P_{1}}^{P_{2}} R_{i} d P
$$

The area under the curve between $\mathrm{P}_{1}$ and $\mathrm{P}_{2}$ is the incremental rate. Similarly, from no load to $\mathrm{P}_{1}$, the increase in input $\mathrm{I}_{1}-\mathrm{I}_{0}$ is given by the area under the incremental rate curve from $\mathrm{P}=0$ to $\mathrm{P}_{1}$, and $\mathrm{Ri}$ is the incremental rate.

By differentiating the expression in equation 1 to the third power, we get the incremental rate characteristic as:

$$
R i=\frac{d I}{d P}=b+2 c(P)+3 d\left(P^{2}\right)
$$

However, the theory of incremental rate assumes the following conditions:

a. That input - output curves are continuous

b. That first derivatives of the input - output curves are continuous

c. That value of the incremental rate increases with the increase in output

Hence to minimize I (input) the condition will be

$$
\frac{d I}{d P}=0
$$

for generators $\mathrm{i}=1$--------- $\mathrm{n}$.

Then

$$
\frac{d I_{1}}{d P_{1}}=0 \quad \frac{d 1_{2}}{d P_{2}}=0 \quad \frac{d I n}{d P n}=0
$$

Hence

$$
\frac{d I_{1}}{d P_{1}}=\frac{d 1_{2}}{d P_{2}}=\frac{d I n}{d P n}=R
$$

Therefore the input will be a minimum for a specified load when the units have the same incremental rate.

\section{Solution to Minimizing Cost of Generation}

With the above background information the objective of generation cost minimization is to schedule generation such that input (I) is minimum for the given total power $P$, subject to restriction that the sum of $\mathrm{P}_{\mathrm{k}}=\mathrm{P}$ (is the total load received), where $P_{k}$ is the output of unit $k$.

Using the lagrangian method, if

$$
f\left(P_{1}, P_{2},--------P_{k}\right)=0
$$

And

$$
\sum_{k=1}^{n} P_{k}-P=0
$$

Then

$$
\sum_{k=1}^{n} P_{k}=P
$$

If I represent the cost of input, the minimum input cost is realized when

$$
\frac{d I_{t}}{d P_{k}}=0 \text { where } I_{t}=\sum_{k=1}^{n} I_{k} \quad I_{\mathrm{t}}=\text { total input }
$$

Applying lagrangian type multiplier where

$$
I=I_{t}-\lambda f \quad \lambda=\text { lagrangian type of multiplier }
$$




$$
\frac{d I}{d P_{k}}=\frac{d I_{t}}{d P_{k}}-\lambda \frac{d f}{d P_{k}}=0
$$

Where $\mathrm{f}$ is the function of total power received ie

$$
\begin{gathered}
f\left(P_{1}, P_{2},----P_{n}\right)=0 \text { or } \sum_{k=1}^{n} P_{k}-p=0 \\
\text { But RHS } \frac{d I_{t}}{d P_{k}}-\frac{\lambda d}{d P_{k}}\left[\sum_{k=1}^{n} P_{k}-P\right]=0 \\
\frac{d I_{t}}{d P_{k}}-\lambda[1-0]=0 \\
\therefore \frac{d I_{t}}{d P_{k}}=\lambda \quad \text { and } \frac{d}{d P_{k}}\left[\sum_{k=1}^{n} I_{k}\right]=\lambda
\end{gathered}
$$

Hence

$$
\frac{d I_{t}}{d P_{k}}=\lambda
$$

The incremental cost of input to $\mathrm{k}^{\text {th }}$ unit in dollar per hour is equal to the incremental cost of the received power.

The equation 10 may be rewritten as

$$
\frac{d I_{1}}{d P_{1}}=\frac{d I_{2}}{d P_{2}}=\frac{d I_{2}}{d P_{3}}---=\frac{d I_{n}}{d P_{n}}
$$

If the incremental rate of $\mathrm{k}^{\text {th }}$ unit is written as $\mathrm{R}_{\mathrm{i}}$, then

$$
\mathrm{R}_{\mathrm{i} 1}=\mathrm{R}_{\mathrm{i} 2}=\mathrm{R}_{\mathrm{i} 3}-----\mathrm{R}_{\mathrm{ik}}=-----\mathrm{R}_{\mathrm{in}}=\lambda
$$

Using symbol, C, for incremental production cost in dollar per hour then:

$$
C i_{1}=C i_{2}=C i_{3}---=C i_{k}--C i n=\lambda .
$$

Where $\lambda$, the lagrangian multiplier, is the incremental cost of received power in dollar per hour.

In other words, suppose we have a five-bus power system network in a one line diagram as shown in Figure 2 , we can develop an computer based algorithm for the optimal distribution cost using the above an analytical solution.

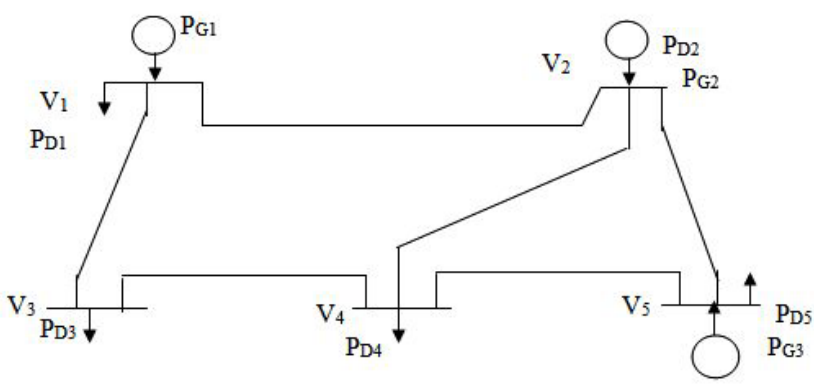

Figure 2. One-Line Diagram of a Five Bus System

\subsection{Algorithm for the Optimal Power Flow of the Five-Bus Network}

For $\mathrm{x}$ MW to be generated from $\mathrm{P}_{\mathrm{G} 1}, \mathrm{P}_{\mathrm{G} 2}$, and $\mathrm{P}_{\mathrm{G} 3}$ (where the $\mathrm{P}_{\mathrm{Gi}}$ 's are of equal capacity) that would service the combined external load $y$ in $\mathrm{P}_{\mathrm{D} 3}, \mathrm{P}_{\mathrm{D} 4}$ optimally i.e. $\mathrm{x}=$ $\mathrm{y}$, we proceed follows:
1. Obtain the cost functions for each of the generators $\mathrm{P}_{\mathrm{G} 1}, \mathrm{P}_{\mathrm{G} 2}, \mathrm{P}_{\mathrm{G} 3}$ as follows:

$$
\begin{aligned}
& \mathrm{C}_{1}=\mathrm{aP}_{1}^{2}+\mathrm{bP}_{1}+\mathrm{c} \\
& \mathrm{C}_{2}=\mathrm{aP}_{2}^{2}+\mathrm{bP}_{2}+\mathrm{c} \\
& \mathrm{C}_{3}=\mathrm{aP}_{3}{ }^{2}+\mathrm{bP}_{3}+\mathrm{c}
\end{aligned}
$$

2. for optimal economic allocation of load y we apply the lagrangian method, where:

$$
\begin{aligned}
& \mathrm{C}_{1}=\mathrm{C}_{2}=\mathrm{C}_{3} \text { and } \mathrm{C}_{1}=\mathrm{dC}_{1} / \mathrm{dP}_{1}, \\
& \mathrm{C}_{2}=\mathrm{dC}_{2} / \mathrm{dP}_{2}, \mathrm{C}_{3}=\mathrm{dC}_{3} / \mathrm{dP}_{3} .
\end{aligned}
$$

3. differentiate the $\mathrm{C}_{1}, \mathrm{C}_{2}$, and $\mathrm{C}_{3}$ with respect to $\mathrm{P}_{\mathrm{G} 1}$, $\mathrm{P}_{\mathrm{G} 2}$, and $\mathrm{P}_{\mathrm{G} 3}$.

4. solve for $\mathrm{P}_{1}, \mathrm{P}_{2}$, and $\mathrm{P}_{3}$ by equating the differential for minimum cost.

5. add $\mathrm{P}_{1}, \mathrm{P}_{2}$, and $\mathrm{P}_{3}$ the total will be equal to $\mathrm{y}$, the total load to service i.e $\mathrm{P}_{1}+\mathrm{P}_{2}+\mathrm{P}_{3}=\mathrm{y}$.

\subsection{Algorithm for the Optimal Cost Savings in the Five-Bus Network}

To obtain cost saving effected by the optimal allocation instead of equal division of load we proceed as:

1. let $\mathrm{P}_{\mathrm{G} 1}{ }^{\prime}, \mathrm{P}_{\mathrm{G} 2}{ }^{\prime}$ and $\mathrm{P}_{\mathrm{G} 3}{ }^{\prime}=\mathrm{x}^{\prime}\left(\mathrm{x}^{\prime}\right.$ is one-third of $\mathrm{x}$ and $\left(\mathrm{P}_{\mathrm{Gi}}{ }^{\prime}\right)$ 's are of equal capacity).

2. obtain the cost function $\left(C_{i}{ }^{\prime}\right)$ 's of $P_{1}{ }^{\prime} P_{2}{ }^{\prime} P_{3}$ as follows:

$$
\begin{aligned}
& \mathrm{C}_{1}{ }^{\prime}=\mathrm{a}\left(\mathrm{P}_{1}{ }^{\prime}\right)^{2}+\mathrm{bP}_{1}{ }^{\prime}+\mathrm{c} \\
& \mathrm{C}_{2}{ }^{\prime}=\mathrm{a}\left(\mathrm{P}_{2}{ }^{\prime}\right)^{2}+\mathrm{bP}_{2}{ }^{\prime}+\mathrm{c} \\
& \mathrm{C}_{3}{ }^{\prime}=\mathrm{a}\left(\mathrm{P}_{3}{ }^{\prime}\right)^{2}+\mathrm{bP}_{3}{ }^{\prime}+\mathrm{c}
\end{aligned}
$$

3. obtain increased cost of input for $P_{1}{ }^{\prime}$ as

$$
\Delta \mathrm{C}_{1}=\mathrm{C}_{1}{ }^{\prime}-\mathrm{C}_{1} \text { per unit }(\$ / \mathrm{h})
$$

4. Saving in cost of input for $\mathrm{P}_{2}{ }^{\prime}$

$$
\Delta \mathrm{C}_{2}=\mathrm{C}_{2}-\mathrm{C}_{2}{ }^{\prime} \text { per unit }(\$ / \mathrm{h})
$$

5. Saving in cost of input for $\mathrm{P}_{3}{ }^{\prime}$

$$
\Delta \mathrm{C}_{3}=\mathrm{C}_{3}-\mathrm{C}_{3} \text { ' per unit }((\$ / \mathrm{h})
$$

6. Net increase cost is

$$
\mathrm{C}_{\text {net }}=\Delta \mathrm{C}_{1}-\Delta \mathrm{C}_{2}-\Delta \mathrm{C}_{3} \text { per unit }(\$ / \mathrm{h})
$$

7. for 24 hours we obtain $C_{\text {day }}=C_{\text {net }} * 24$ hours, $C_{\text {day }}$ is the daily cost saving for running the three generators.

\section{Results}

Results obtained from 'Lantool' decision support application is shown in Table 2 for various load demands. As expected the difference between operating the station optimally as against equal distribution is clearly identified in the table as NetSave. The daily cost saving (NetSave) for each of the load demands per day is also shown.

\section{Discussion}

In the analysis of optimal load division between the various units of a plant, it is expected that the available 
data on cost is absolutely correct. The implementation of the 'Lantool' program is based on data set for the test cases of Table 1 . The table shows generator input cost data as $\mathrm{C} 1, \mathrm{C} 2$, C3, while P1, P2, P3, are power generated data for $\mathrm{P}_{\mathrm{g} 1}, \mathrm{P}_{\mathrm{g} 2}$, and $\mathrm{P}_{\mathrm{g} 3}$ respectively for the five-bus network in Figure 2. The input cost function is derived from equation 3 with all coefficients positive. (The coefficients for input cost equations are obtained using Matlab Curve Fitting Toolbox). Line plots of cost versus power output is shown in Figure 3. The optimum economy is achieved if every unit (i.e. $\mathrm{P}_{\mathrm{g} 1}, \mathrm{P}_{\mathrm{g} 2}$, and $\mathrm{P}_{\mathrm{g} 3}$ ) operates at the same incremental cost(IC) as seen in Figure 4. At any point on the incremental cost plot, the three generators are operated optimally and fuel utilization is seen to be less. Screen shots of cost with output of simulation, daily cost saving and incremental cost plot/data is shown in Figure 5 and Figure 6 . The output of daily net saving per load demand when multiplied by 30 days will give the cost savings per month.

Table 1. Sample of output power and cost of input in \$ per hour

\begin{tabular}{|c|c|c|c|c|c|}
\hline P1 (MW) & P2 (MW) & P3 (MW) & C1 (\$/hour) & C2 (\$/hour) & C3 (\$/hour) \\
\hline 24.1 & 24.1 & 24.1 & 598.7405 & 581.8886 & 503.3648 \\
\hline 20.8 & 20.8 & 20.8 & 535.232 & 525.4784 & 461.8112 \\
\hline 21.5 & 21.5 & 21.5 & 548.6125 & 537.335 & 470.48 \\
\hline 22.3 & 22.3 & 22.3 & 563.9645 & 550.9574 & 480.4832 \\
\hline 16.6 & 16.6 & 16.6 & 455.978 & 455.5736 & 411.4448 \\
\hline 22.7 & 22.7 & 22.7 & 571.6645 & 557.7974 & 485.5232 \\
\hline 22.9 & 22.9 & 22.9 & 575.5205 & 561.2246 & 488.0528 \\
\hline 22.7 & 22.7 & 22.7 & 571.6645 & 557.7974 & 485.5232 \\
\hline 25.3 & 25.3 & 25.3 & 622.1045 & 602.7254 & 518.9072 \\
\hline 23.4 & 23.4 & 23.4 & 585.178 & 569.8136 & 494.4048 \\
\hline 24.2 & 24.2 & 24.2 & 600.682 & 583.6184 & 504.6512 \\
\hline 25.1 & 25.1 & 25.1 & 618.2005 & 599.2406 & 516.3008 \\
\hline 23.6 & 23.6 & 23.6 & 589.048 & 573.2576 & 496.9568 \\
\hline 22.4 & 22.4 & 22.4 & 565.888 & 552.6656 & 481.7408 \\
\hline 22 & 22 & 22 & 558.2 & 545.84 & 476.72 \\
\hline 23.3 & 23.3 & 23.3 & 583.2445 & 568.0934 & 493.1312 \\
\hline 17.3 & 17.3 & 17.3 & 469.0645 & 467.0774 & 419.6432 \\
\hline 22 & 22 & 22 & 558.2 & 545.84 & 476.72 \\
\hline 25.7 & 25.7 & 25.7 & 629.9245 & 609.7094 & 524.1392 \\
\hline 22.7 & 22.7 & 22.7 & 571.6645 & 557.7974 & 485.5232 \\
\hline 26.1 & 26.1 & 26.1 & 637.7605 & 616.7126 & 529.3968 \\
\hline 26.2 & 26.2 & 26.2 & 639.722 & 618.4664 & 530.7152 \\
\hline 24.3 & 24.3 & 24.3 & 602.6245 & 585.3494 & 505.9392 \\
\hline 25.9 & 25.9 & 25.9 & 633.8405 & 613.2086 & 526.7648 \\
\hline
\end{tabular}

Table 2. Sample result of Optimal vs Equal distribution cost from LanTool per load demand

\begin{tabular}{|c|c|c|c|c|}
\hline EQD & L1 & L2 & L3 & L4 \\
\hline Load & 55.0001 & 75.0001 & 90.0001 & 100.0001 \\
\hline Gen1cost & 488.472 & 616.25 & 715 & 920 \\
\hline Gen2cost & 484.167 & 597.5 & 686 & 872 \\
\hline Gen3cost & 431.889 & 515 & 582 & 728 \\
\hline & & & & \\
\hline OPD & & & & \\
\hline Load & 55.0001 & 75.0001 & 90.0001 & 100.0001 \\
\hline Gen1cost & 173.8032 & 323.5005 & 439.5947 & 686.107 \\
\hline Gen2cost & 427.0709 & 539.0336 & 625.8461 & 810.2329 \\
\hline Gen3cost & 716.8009 & 791.6816 & 849.8279 & 973.0873 \\
\hline & 2084.471 & 1788.825 & 1625.552 & 1213.746 \\
\hline NetSave & 2084.471 & 1788.825 & 1625.552 & 1213.746 \\
\hline
\end{tabular}

Key: EQD = Equal Distribution of load. OPD = Optimal Distribution of load : L1,L2,L3,L4 = load demand (MW).

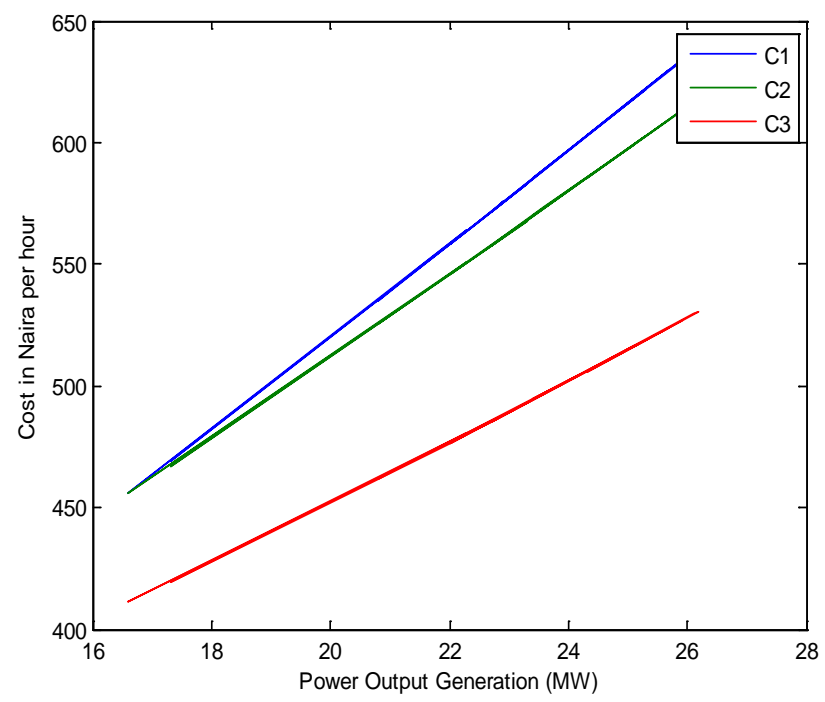

Figure 3. Line Plots of Cost vs Power output Generated for $\mathrm{P}_{\mathrm{g} 1}, \mathrm{P}_{\mathrm{g} 2}$, and $\mathrm{P}_{\mathrm{g} 3}$ 


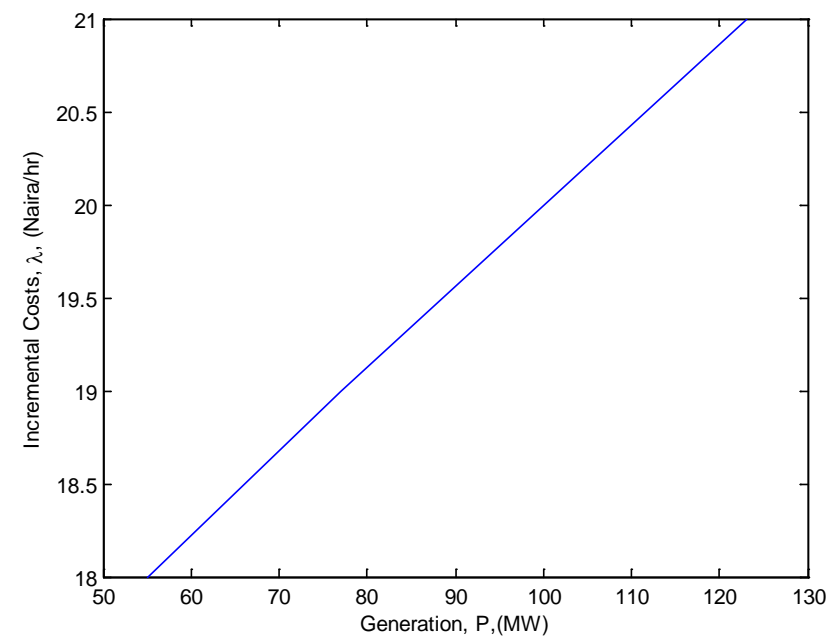

Figure 4. Line Plot of Incremental Cost (Dollar) vs Total Output (MW) $\mathrm{P}_{\mathrm{g} 1}, \mathrm{P}_{\mathrm{g} 2}$, and $\mathrm{P}_{\mathrm{g} 3}$

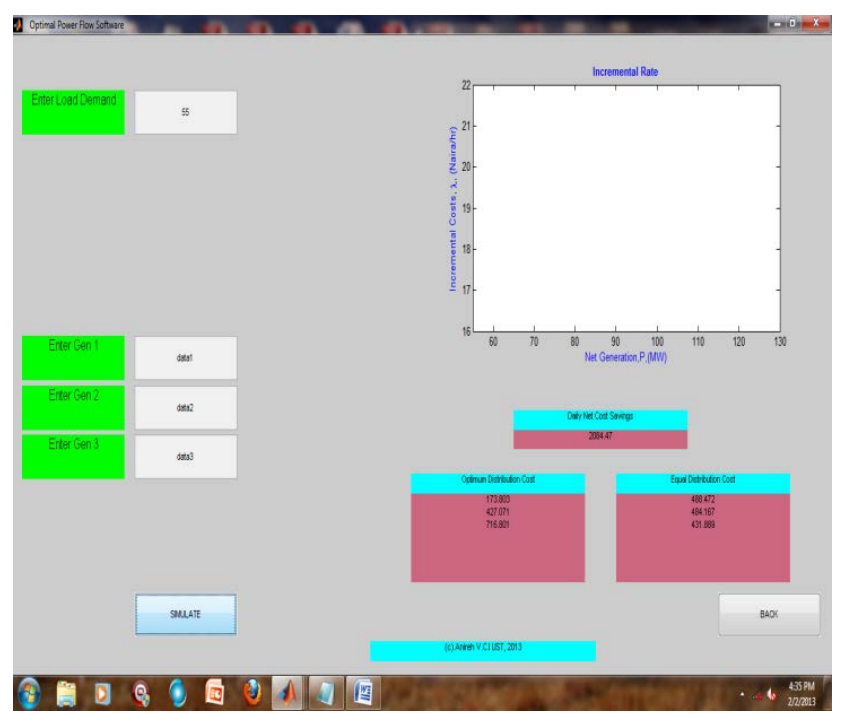

Figure 5. Sample screen for the lagrangian Optimal/Equal distribution cost with output of simulation and daily cost saving data

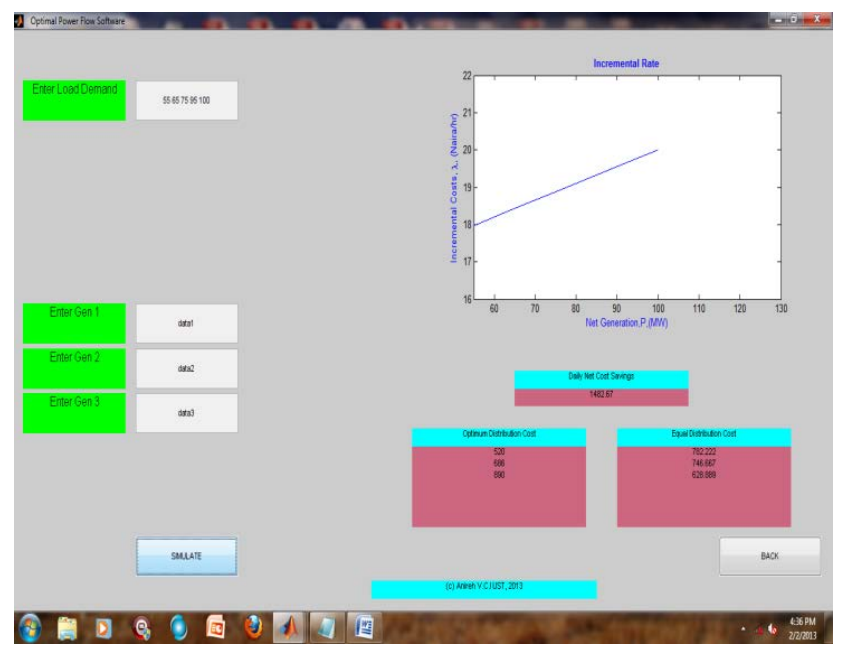

Figure 6. Sample screen for the lagrangian Optimal/Equaldistribution cost with output of simulation, daily cost saving and incremental cost plot/data

\section{Conclusion}

Minimizing cost of fuel in generating electricity is a real world problem and requires practical solution. The paper presented lantool, a decision support application tool designed to determine the best combination of power generating plant to produce electricity with less fuel cost. It was formulated using the lagrangian multiplier method and developed as an interactive application for operators at gas turbine generating (GTG) plant. The design uses a special object oriented methodology feature of MatLab called handle graphics technology (HGT). This approach provides the application with menu-driven guides that would enable operators with little knowledge of computer navigate through it without difficulty. Lantool can be extended to include an embedded form. When interfaced with a sensor can automatically control the switching of power plant for optimal operation. Simulation data from other stations tested on lantool show no significant difference in result implying that the system can be deployed in a dissimilar geographical location.

\section{References}

[1] Dongxiao N, Yanan W. "A novel social-environmental-economic dispatch model for thermal/wind power generation and application" International Journal of Innovative Computing, Information and Control (ICIC). 9(7), 2013.

[2] Alrashidi M.A, Hawary M.E., "Impact of loading conditions on the emission economic dispatch". Proceedings of World Academy of Science, Engineering and Technology, 2008.

[3] Wang L, Chanan S., "Reserve constrained multiarea environmental/economic dispatch based on particle swarm optimization with local search". Engineering Application of Artificial Intelligence Science Direct, 2008.

[4] Peixoto, H.M., Guerreiro, A.M.G., Dória Neto, A.D., "Image processing for eye detection and classification of the gaze direction”, Proceedings of the 2009 International Joint Conference on Neural Networks, Atlanta, GA, USA. pp. 24752480, 2009.

[5] Sambo A.S., "The Challenges of Sustainable Energy Development in Nigeria”. Presentation to Nigerian Society of Engineers, Abuja, Nigeria, 2009.

[6] Palma-dos-Reis, A., Zahedi, F. M., "Designing personalized intelligent financial support systems”. Decision Support System, 26(1): 31-47, 1999.

[7] Martinez L.J., Lora T.A., Santos R.J., “Short term hydrothermal coordination based on interior point nonlinear programing andgenetic Algorithm”. IEEE Porto Power Tech Conference, 2001.

[8] Shi C.C., Chun H.C., Fomg I-K, Lah P.B., "Hydroelectric generation scheduling with an effective differential dynamic programming algorithm”. IEEE Transactions on Power System, 1990.

[9] Erion F., Silva E, Laudia S., "Solving the unit commitment problem of hydropower plants via Lagrangian relaxation and sequential quadratic programming”. Journal of Computational \& Applied Mathematics, 2005.

[10] Tkayuki S., Kamu, W., Lagrangian relaxation method for price based unit commitment Problem. Engineering Optimization, Taylor Francis, 2004.

[11] Huang J.S., "Enhancement of hydroelectric Generation scheduling using ant colony system based optimization approaches". IEEE Transactions on Energy Conversion, 2001.

[12] Mantawy A, Abdel-Magid Y., Selim S., “A simulated annealing algorithm for unit commitment”, IEEE Trans. Power Syst., 13(1): 197-204, 1998.

[13] Naresh R, Sharma J., "Short term hydro scheduling using two phase neural network”. International Journal of Electrical Power and Energy Systems, 2002.

[14] Liu, D., Dong X., Shi, P., “The optimization based on improved membrane algorithm for fuzzy RBF neural network control of ball-plate system”, ICIC Express Letters, Part B: Applications, 3(5): 1259-1267, 2012.

[15] Lopes, D.C., "Implementation of a Modular Neural Network in a Multiple Processor System on FPGA to Classify Electric Disturbance”. Industrial Electronics. IECON '09. 35th Annual Conference of IEEE, Porto, Portugal, 2009. 
[16] Lee, T.E, Su, J.P., Yu K.W., "Fuzzy gain scheduled alpha-betagamma filter design based on particle swarm optimization method”, ICIC Express Letters, 4(6B): 2305-2310, 2010.

[17] Kazarlis, S., Bakirtzis, A., Petridis, V., "A genetic algorithm solution to the unit commitment problem", IEEE Trans. Power Syst., 11(1): 83-92, 1996.

[18] Lin, W.M, Cheng, F.S, Tsay, M.T., "An improved Tabu search for economic dispatch with multiple minima". IEEE Transaction on Power System, 2002.

[19] Jie, X, Deyun, X., "New Metropolis coefficients of particle swarm optimization”, IEEE, 2008.
[20] Liao, G., “A novel evolutionary algorithm for dynamic economic dispatch with energy saving and emission reduction in power system integrated wind power”, Energy, 36: 1018-1029, 2011.

[21] Yang, H.T, Yang, P.C, Huang, C. L., "Evolutionary programming based economic dispatch for units with non smooth fuel cost function”, IEEE Transaction on Power System, 1996.

[22] Information and Telecommunication Technologies Peixoto, H.M., Cruz, R. M.S., Guerreiro, A.M.G., Dória Neto, A.D., D’Assunção, A.G., "A comparison of multilayer perceptrons training algorithms for the optimization of frequency selective surfaces", Proceedings of 8th International Symposium, Florianopolis, SC, Brazil, 2009.

[23] Gangadhar, K.A. "Electrical Power Systems". Khanna Publishers. Nai,Sarak, Delhi. India, 2006. 